\title{
CONSTRUCTION AND APPLICATION OF A GEOTECHNICAL DATABASE FOR PREPARATION OF ENGINEERING GEOLOGICAL MAPS FOR NORTHWESTERN IRAN
}

\author{
Jafar Ghayoumian*1, S.Mahmoud Fatemi Aghda*1, Katsuaki Koike*2, \\ Eitaroh Doi ${ }^{* 1}$, M.A. Nogole Sadat ${ }^{* 3}$, and Shigeki Nakajima*2 \\ $* 1$ Graduate School of Kumamoto University, Kumamoto, Japan \\ $* 2$ Faculty of Engineering, Kumamoto University, Kumamoto, Japan \\ *3 Geological Survey of Iran, Tehran, Iran
}

\begin{abstract}
A geotechnical database has been developed to act as a system for management tool for site investigation data. The system runs on a microcomputer and is capable of producing several sets of geotechnical maps and cross sections.

The resulted analytical maps, clarify those factors, connected with soil features and their geotechnical nature which are of interest to engineers and planners for preliminary site evalu ation.

The engineering geological maps have the advantage that every one can give his/her own personal interpretation using such a map.

The paper describes the database system and provides some of its applications in illustra tion of horizontal and vertical transition of lithofacies, modeling of groundwater flow, maps of $N$ value and lithology in the horizontal plane for arbitrary depths, vertical changes of $N$ values and lithology data, preparation of subsurface cross sections, dominate frequency analysis of the ground shake and cluster analysis of $N$ values data.
\end{abstract}

Key Words : Database, Engineering geological maps, Lithofacies, Groundwater, $N$ value, Cluster analysis

\section{INTRODUCTION}

Data are facts, represented by characters, num bers or symbols which carry meaning in a certain context. Computer programs direct and manipulate data within a computer system (Bellotti et al. 1991).

The uses of computer for the management of geotechnical data have been involved in a number of steps over the past 20 years (Bottino and Civita, 1986).

Boring data which are the main obtainable data during site investigation give significant information about subsurface conditions. If this information is systematically managed in a form of engineering geo logical maps, it can be used as vital tools for prelimi nary site evaluation.

It is rarely practical from a cost - benefit point of view to compile sets of derivative maps by hand. To assist the input of geotechnical information in to the planning processes at a regional scale, the geotechni cal information is summarized into a computer database for the production of engineering geological maps. Review of literatures reveal much effort for da ta and information management during last three years, i.e., Walters and Lioyd (1985), Chaplow (1986), Hayashida, et al. (1988), Nakayama, et al.(1990), Bently and Stenning (1990), Coulthard, et al. (1990), Forster(1990), Herbschleb(1990) and Zong and Fang.

In this paper, a database system is introduced for management tools of a vast quantity of diverse geotechnical data. The purpose of the developed database is the administration, management and presentation of borehole logs in forms of engineering geological maps using a computer system. The aim is to explore new, faster, better or cheaper ways of mak ing predictions in engineering geology.

In this task the system is used to clarify the re gional geotechnical characteristics of Gilan plain. The aim is to reveal subsurface conditions in the area and to estimate vibration property of ground for earth quake.

\section{STUDY AREA}

The study area is located in the Northwestern part of Iran, south part of Caspian sea (Gilan plain).

The relief of the area is very marked and a range of altitude from 28 meter below mean sea level on the Caspian shore to the more than 3300 meter on the Agh Dash is encountered.

The Caspian depression is occupied by sea in the Northeast and by alluvial and coastal sediments on the Gilan plain. The depressed area is clearly of tec tonic origin and the natures of the hill front to the West suggest that its limits may be determined by ex tensive faults which are now buried beneath the sedi ments of the coastal plain (Davies, Hamzepour, et al., 1975).

Geological map of the study area is illustrated in Fig.1. Resent deposits of the Caspian plain occur mainly as a belt of marine alluvium adjoining the coast and as deltaic deposits of rivers flowing into the Caspian sea. Pleistocene deposits, partly marine and partly fluviatile or deltaic in origin, form terraced and outcrops further inland rising to about $200 \mathrm{~m}$. 


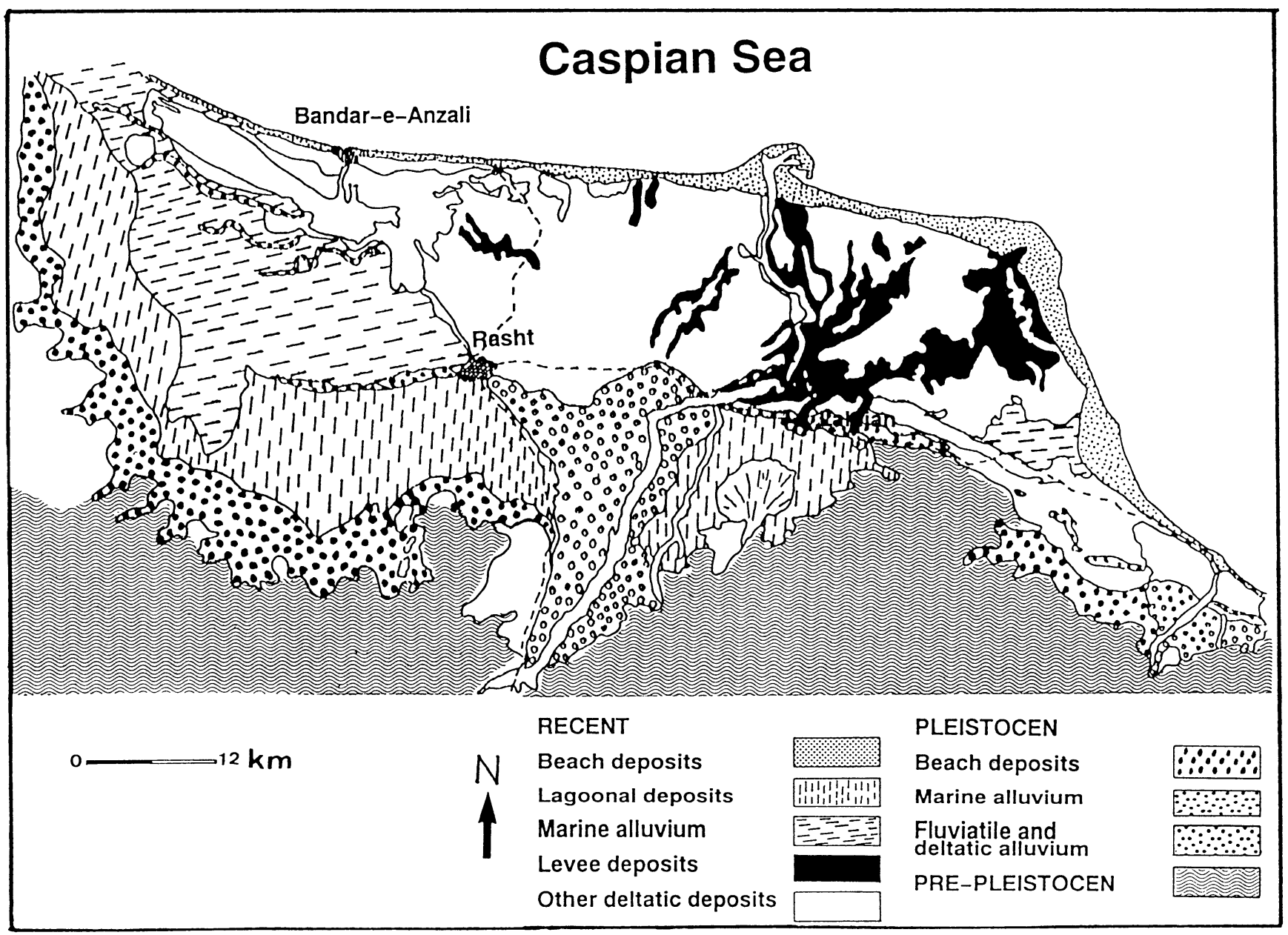

Fig.1. Geological map of the study area

The highest deposits occur at about $220 \mathrm{~m}$ and are preserved as a small patch of sand and gravel resting on Carboniferous phyllites about $17 \mathrm{~km}$ South of Rasht. The present - day beach deposits consist large ly of sand. The younger Quaternary terrace features of the Caspian littoral are severely disrupted by the Sefid Rud delta and other smaller rivers to the east. Most of the lower terraced deposits, which are regarded as having accumulated under the influence of Caspian sea level, rest on irregular surface of Neo gene rocks (Annells, 1991 ).

The area suffered a catastrophic earthquake in 1990. As the area is located in one of the most haza rdous seismic zones of Iran and subsurface materials are weak, for re-construction procedures in the area engineering geological evaluation is considered as a vital tool for planners and engineers in this respect.

\section{DATABASE SYSTEM}

The database system is managed to be capable to store and manipulate borehole logs which include geotechnical information. The overall concept of the system depends upon creation of a series of data files, each file containing all site investigation information of an individual borehole.

There are programs to allow information to be en tered into the files, for correction of stored data, also different types of engineering geological maps can be produced from the stored data using retrieval programs. The data file for each individual borehole has a fixed format to allow random access to it and com prises different parts to hold the variety of the data required.

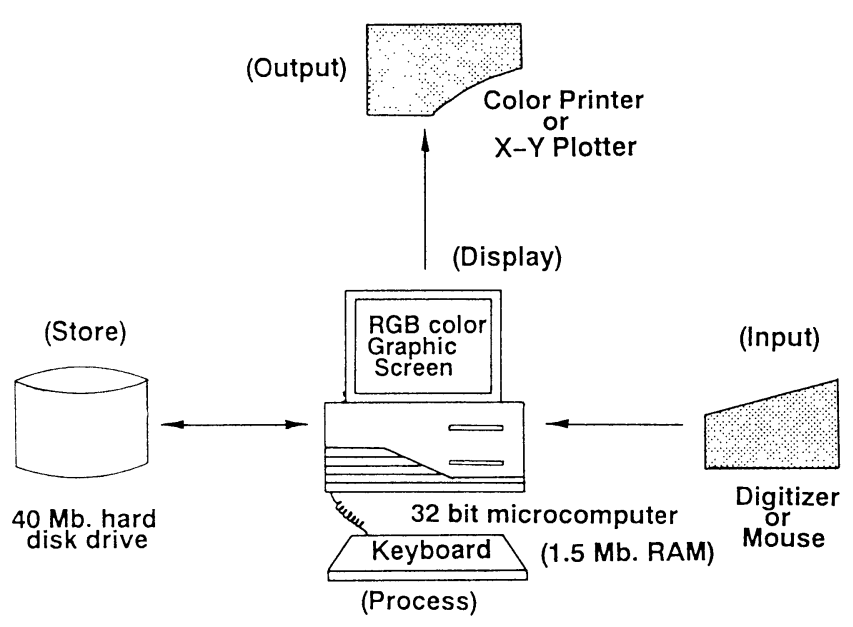

Fig.2. Configuration of the hard in current use 
The system is mounted on a microcomputer and the retrieval programs are written in the BASIC lan guage. The hardware for the geotechnical database consists of a microcomputer with 1.5 Megabytes of random access memory (RAM), a 40 Megabytes hard disc drive, a RGB color graphic screen, a digitizer, a color printer, and an X - Y plotter(Fig.2).

\section{DATA PROCESSING}

The geotechnical information from 154 site inves tigation reports was assembled from borehole record collections. The reports contain a total of more than 400 pit and borehole logs mostly up to 10 meters depth from which geotechnical data were extracted. Old borehole data or badly written reports were rejected. For each borehole the following information was stored into the computer database.

1)Borehole name, latitude,longitude, and altitude of boring site.

2)Groundwater level in the borehole.

3)Lithofacies information: depths to the bottom of each unit, the coded soil name.

4)Geotechnical test results: such as $N$ value of standard penetration test, density, moisture content, at terberg limits, and particle size distribution.

Due to diverse type of soil parameters, in this study only lithofacies and $N$ value data were selected for analysis. Obviously the same kind or similar analyses can be applied for the other parameters easi ly.

In order to have better image from borehole loca- tion, at first some of the main features of the study area such as seashore, location of the main rivers, were traced using a digitizer and the information were entered into the computer.

\section{LITHOFACIES ANALYSIS}

The subsurface soil types (particle size) control geotechnical characteristics of the superficial layers. Thus soil type can give some initial impression of soil behavior such as its permeability, potential of stabili ty, etc.

The primary aim of the collection of site investi gation data is to construct a local stratigraphy of the superficial deposits in relation to the engineering project planned.

The constructed database system can be used to reveal a superficial deposit's lithology in the horizon tal plane for arbitrary depths or elevations which are significant from geotechnical and stratigraphy point of view respectively. The map can be made at every required depth or elevation in the subsurface. A sim ple lithological description of the layers (i.e. Gravel, Sand, Silt, and Clay) was considered to be the output result.

For example the retrieval of lithology at the depths of 5 meters and 15 meters are performed to identify superficial conditions in the Gilan area (Figs. $3,4)$. Clearly sandy and silty soils are accumulated at 5 meters depth in Lahijan and Anzali area, while Rasht area mostly is covered with clay type of soils. Distribution of sandy and silty soils in the Lahijan

\section{$49^{\circ} 00^{\prime}$}

$50^{\circ} 00^{\prime}$

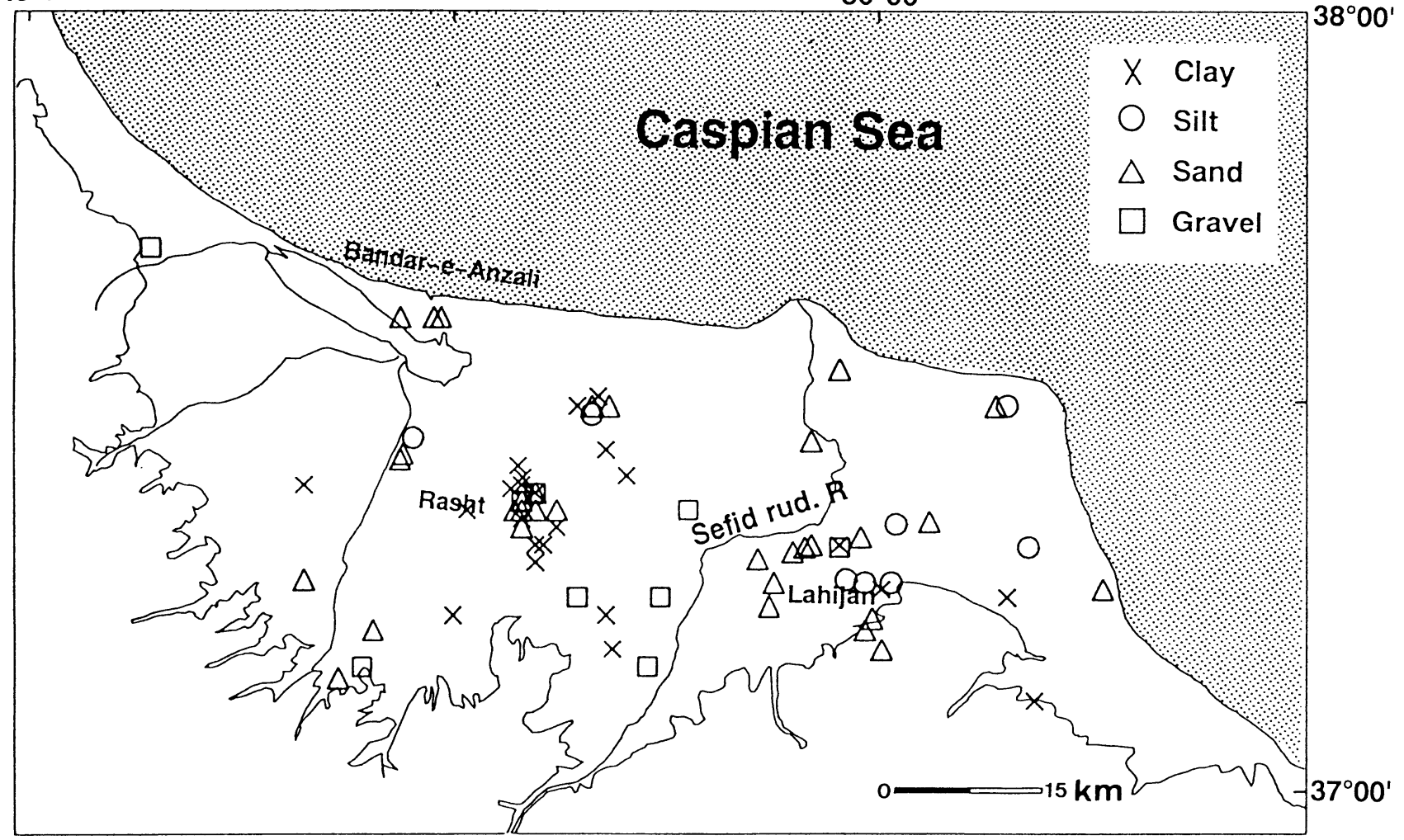

Fig.3. Distribution of lithology at depth 5 meter in the subsurface of Gilan plain 


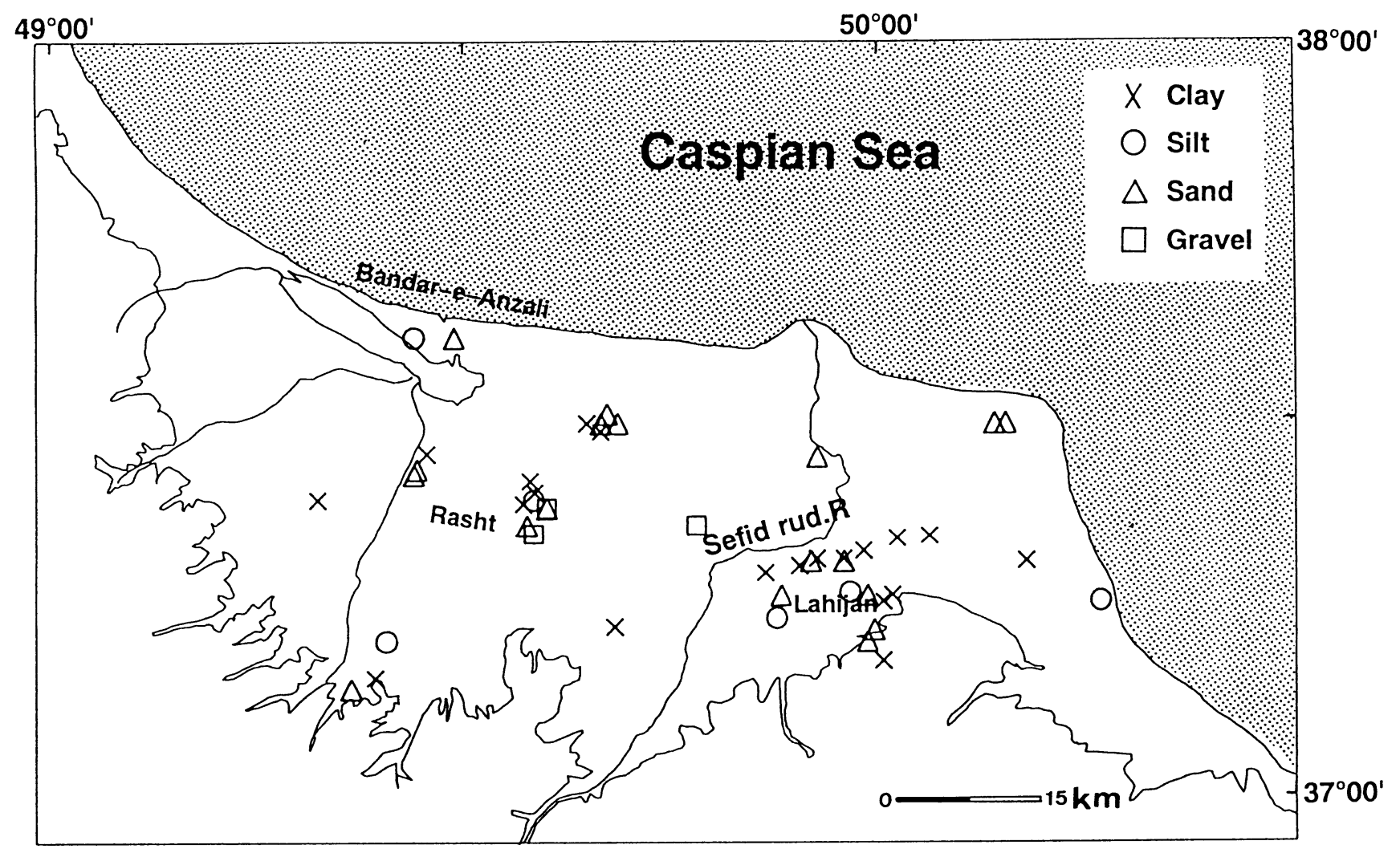

Fig.4. Distribution of lithology at depth 15 meters in the subsurface of Gilan plain

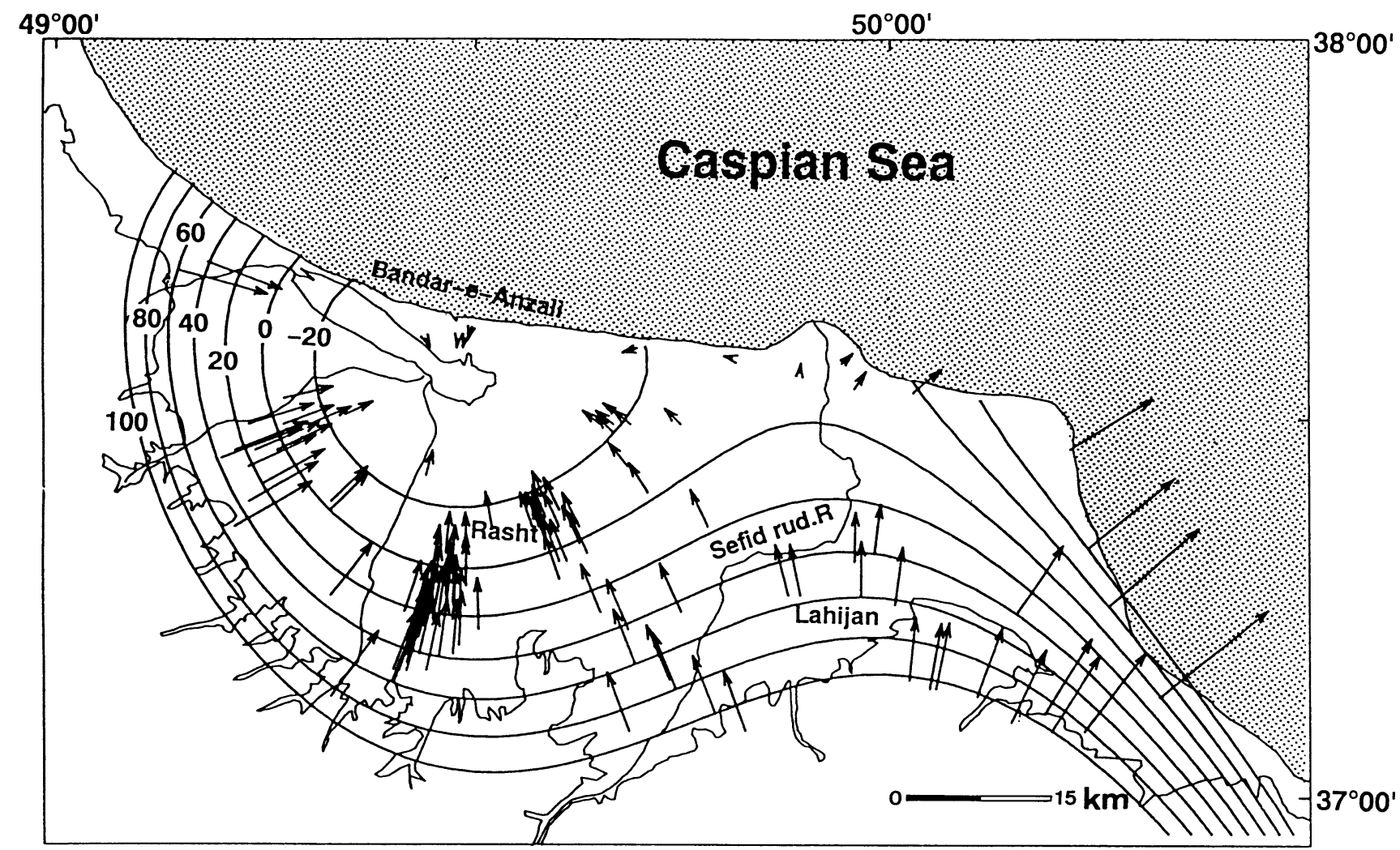

Fig.5. Modeling of the groundwater flow as produced by the trend surface analysis 
and Langroud area might be attributed to the aban doned bed of Sefid Rud river. At depth 15 meters, dis tribution of clay deposit in the Lahijan area also in creases. This might be related to the changes of the Caspian sea level. Paleogeographical interpretation may be performed by comparison of the lithology at the same elevation.

\section{MODELING OF THE GROUNDWATER FLOW}

The groundwater level of the boreholes stored in the database were used for modeling of groundwater flow.

For modeling of groundwater flow, the method proposed by Koike, et al. (1990) was applied. Groundwater level faces to the seasonal fluctuations. The rate of fluctuations varies with respect to the time and locations. To overcome these problems, the water table is assumed to be smooth in area then the poly nomial surface analysis can be used for groundwater modeling.

The equation for a polynomial surface of $m$ th order has the

form:

$$
f(x, y)=\sum_{r=0}^{m} \sum_{k+l=r} a_{k l} x^{k} y^{l}
$$

Where:

$k, l: 1,2, \ldots . . m$

$a_{k 1}$ : Coefficients calculated using the least squares method

In weighted least squares the following expres sion should be minimized.

$$
S=\sum_{i=1}^{m} w_{1}\left\{z_{i}-f\left(x_{i}, y_{i}\right)\right\}^{2}
$$

Where:

$w_{i}$ : the weight assigned to the ith $\operatorname{datum} Z_{i}$

$\mathrm{n}$ : is number of data

Koike, et al. (1990) regarded the weight wi as the in verse fluctuation range of the water table in a year at the point $\left(x_{i}, y_{i}\right)$, but in this study the weight is 1.0 for all the data.

Optimum order of the polynomial trend surface can be determined from the value of AIC (Akaike's Information Criteria) (Akaike, 1973).

$$
A I C=n \log _{e} 2 \pi+n \log _{e} Q+n+2(C+1)
$$

Where:

$Q$ : the deviation of the residuals.

$C:$ the number of coefficients used in the polynomial surface.

The polynomial surface which minimizes the AIC is regarded as the best model to characterize the re gional trend in the data.

When the polynomial surface is identified, the maximum slope (gradient) $R_{i}$ through the point ( $x_{i}$, $y_{i}$ ) on the surface and its orientation i are given as fol lows:

$$
\begin{aligned}
& R_{i}=\sqrt{\left\{\frac{\partial f(x, y)}{\partial x}\right\}^{2}+\left\{\frac{\partial f(x, y)}{\partial y}\right\}^{2}} \\
& \alpha_{i}=\tan ^{-1}\left\{\frac{\partial f(x, y)}{\partial y} / \frac{\partial f(x, y)}{\partial x}\right\}
\end{aligned}
$$

Assuming uniform permeability for the aquifers in the area, $R_{i}$ and $\alpha_{i}$ are considered as gradient of water flow and its direction at the point $\left(x_{i}, y_{i}\right)$ respec tively.

The result of modeling is shown in Fig 5 . The polynomial surface of third order minimizes the value of AIC.

It can be understood that in general groundwater flows from the plain toward Caspian sea. Groundwa ter in the central parts (Rasht area) move toward north part, and is discharged into the sea near Mordab Anzali. Also it can be interpreted that, Sefid Rud in some locations recharge the groundwater and in some parts the groundwater is discharged into the Sefid Rud river.

\section{GEOLOGICAL AND GEOTECHNICAL CROSS SECTION}

The compilation of field recorded data into logs and replotting of the data for drawing cross sections is a critical part of any site investigation.

The database system can be used for preparation of any arbitrary subsurface cross section. The user can choose any optional cross section using a mouse on a graphic screen to produce fence diagrams which involve the logs of boreholes located at a certain dis tance from the cross section line. No interpolation is involved as the diagram represent user nominated se quence of boreholes.

Fig. 6 shows a cross section from north part of Lahijan to the south part of Bandar - e - Anzali for the investigated area which is drawn from Lahijan to the Northwest of the area. The cross section clarifies dis tribution of sandy soils in the Lahijan and its transi tion to the clay type of soils in the Northwestern part of the area.

\section{$N$ VALUE ANALYSIS}

The number of blows per foot, namely $N$ value, is a valuable indicator for illustration of ground resistiv ity against penetration. It can quite closely calibrate against the angle of shearing resistance and against Terzaghi's bearing capacity factors $N_{\mathrm{a}}$ and $N_{\mathrm{r}}$ or density of the superficial layers.

1. Horizontal and vertical distribution of $\mathrm{N}$ values data

Due to significance of $N$ value as an engineering parameter for evaluation of superficial resistivity, it is valuable to construct maps on the basis of this param eter. The developed system is capable to perform maps of $N$ values and lithology in the horizontal plane 

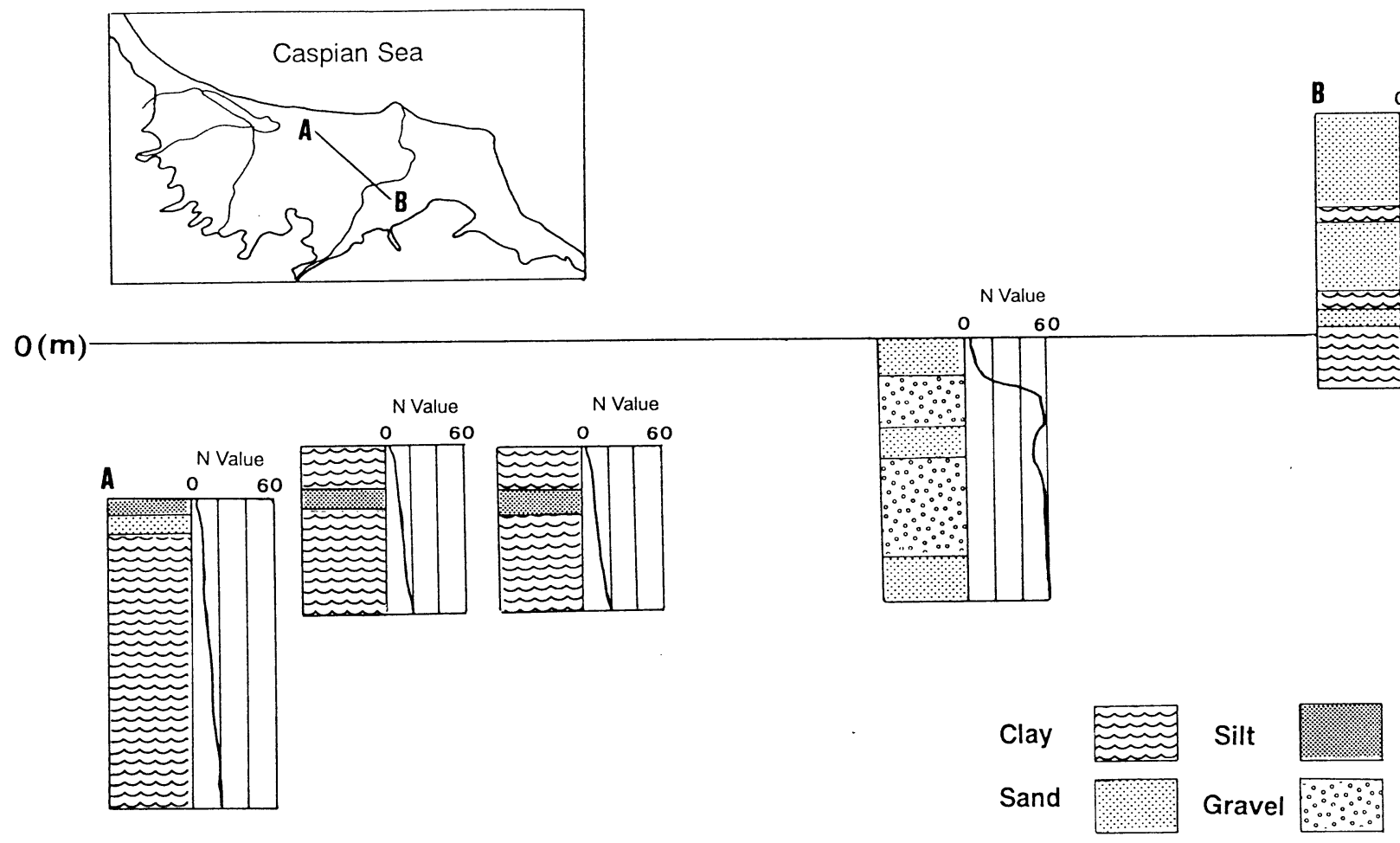

Fig.6. A cross - section from the study area

for diverse depths, which also can be repeated at any desirable depth or level in the subsurface. Figs. 7 and 8 are examples of such kind of maps, which indicate that in general the subsurface of the area at the depth 5 meters consists almost entirely of unconsolidated deposits. By increasing the depth $N$ value also increases in the central and eastern parts of the area.

In geotechnical boreholes $N$ values data usually are not available for 1.0 meter interval for all of the depths. For preparation of $N$ value maps and also for clustering of the $N$ values data, the lithology of the upper and deeper layers having $N$ value were consid ered to interpolate the $N$ value for the desired depth. For this purpose one of the following two lithological patterns were considered.

1)For a desired depth which the $N$ value is unknown, if the lithology of the upper and deeper layers having $N$ values are identical, linear inter polation based on the two $N$ values is performed.

2)If the lithology of the upper and deeper layers are different from each other, the $N$ value of the layer having the same lithology is used as the one at the desired depth.

\section{Foundation Strata}

In general a stratum having $N$ value of 30 or high er with at least 3 meters thickness is considered to have feasible conditions for foundation of major buildings. The depths to the top of such a stratum and its lithology are also obtainable from the database easily. Fig.9 illustrates the location of the boring and the depth of the strata that satisfies the above men- tioned conditions. It is clear, such subsurface layers are very few, but in the location which the conditions exist the foundation strata are very shallow (5 to 10 meters depth).

3. Dominate frequency analysis of the ground shake.

In major buildings design, earthquake-proof consideration is usually taken based on the dominant frequency of the ground shake at the building site. The frequency is determined through the microtremor measurement at the site and the spectral analysis of the data. The database is also applied to estimate dominant frequency of the ground shake. For this purpose, the shear wave velocity Vs was cal culated using the following empirical equation which is obtained for typical fine grained soils in Japan.

$$
V=85.34 \bar{N}^{0.348}
$$

where $\bar{N}$ is the average of $N$ vales of the first layer (the layers which overlie the foundation bearing strata).

Dominant frequency $F_{o}$ is then may be estimated by the quarter of wave length.

$$
F_{0}=V s / 4 H
$$

where $\mathrm{H}$ is the thickness of the first layer. The results of the calculated dominant frequency is presented in Fig 10. It is clear that the calculated dominant fre quency for the area are mostly higher than 4.0, and it increase toward south part of the area. 


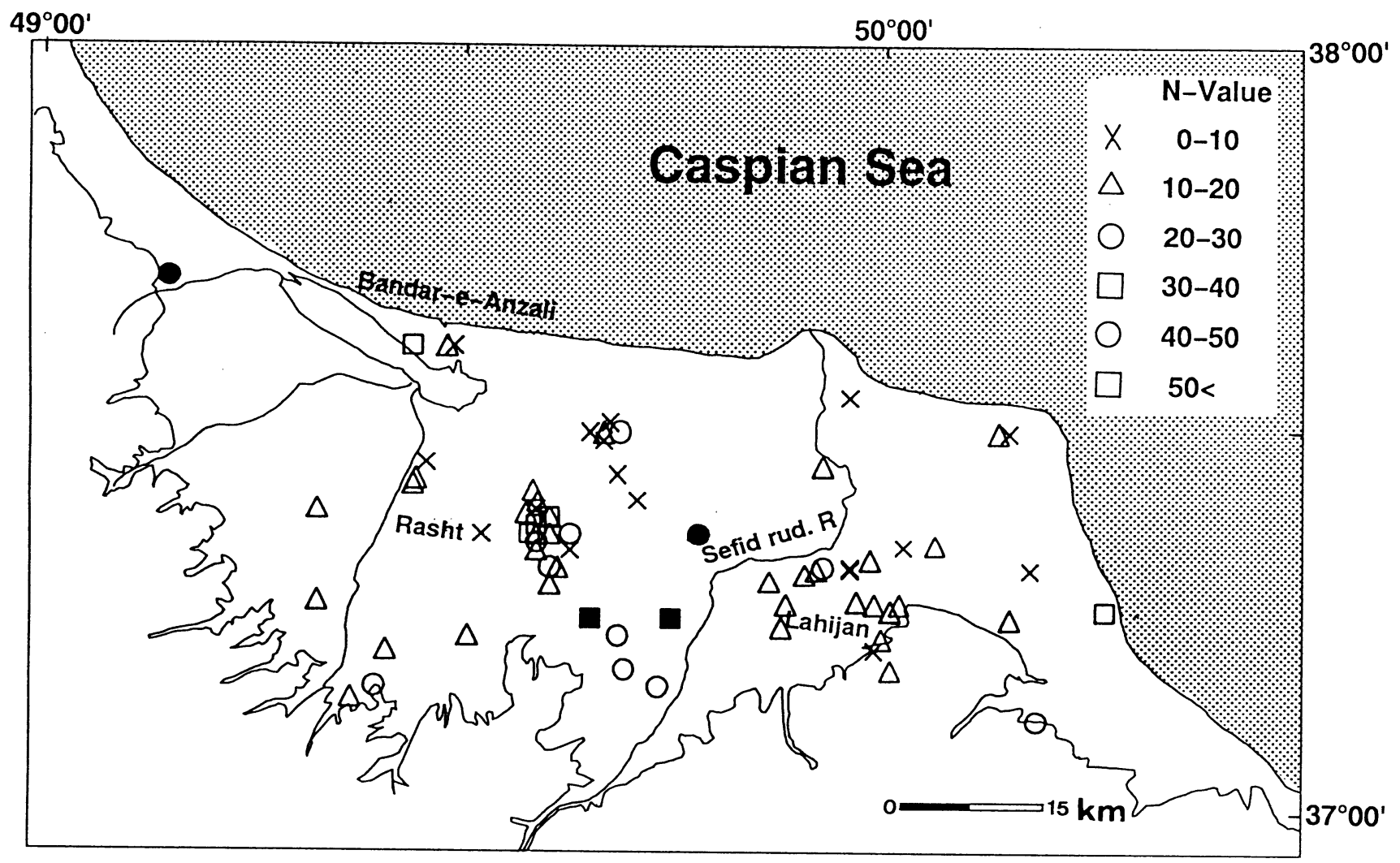

Fig.7 $N$ value rate at depth 5 meter in the subsurface of Gilan plain

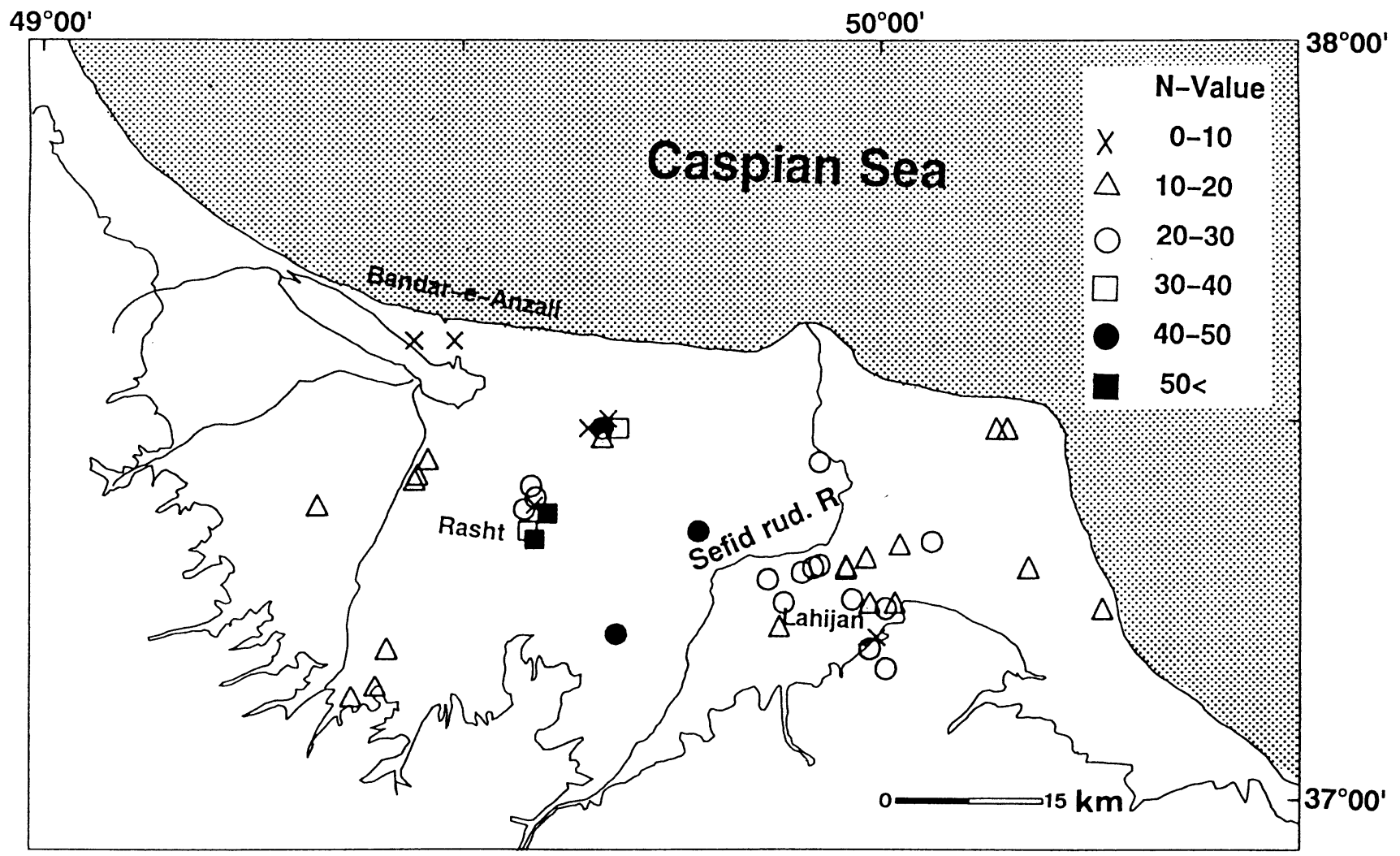

Fig: $8 N$ value rate at depth 15 meter in the subsurface of Gilan plain 


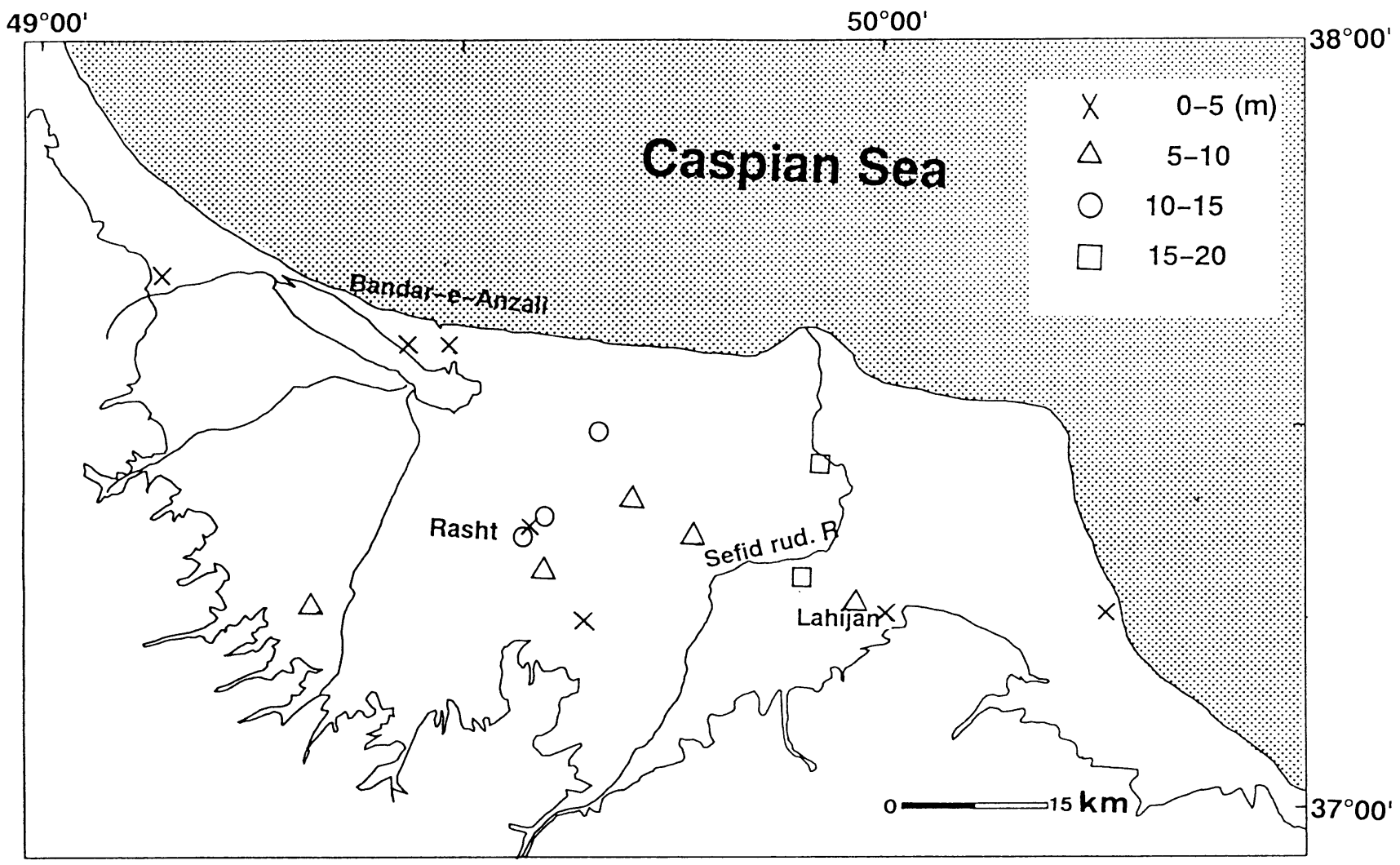

Fig.9. Depth up to the top of the foundation bearing strata

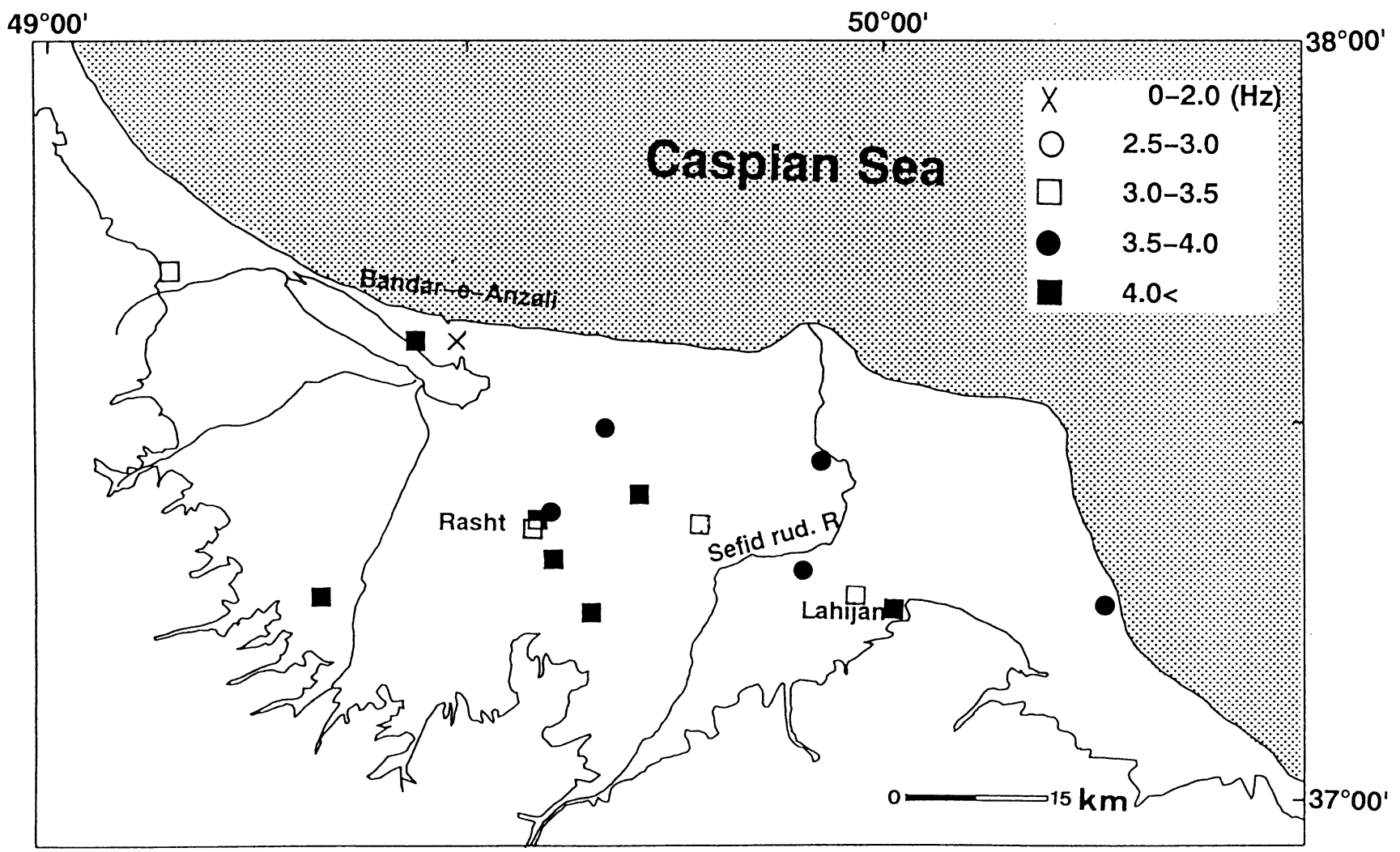

Fig.10.Dominate frequency map of the ground shake, estimated from the $N$ values data 


\section{Clustering of $N$ values data}

In order to find out about the similarities of verti cal changes in geotechnical properties of the subsur face layers, cluster analysis was applied. $N$ value as a parameter which is affected by the lithofacies charac teristics of subsurface layers was used. For this pur pose $N$ values and their vertical changes up to 15 me ters depths at 1.0 meter intervals were utilized. For clustering of $N$ values data we have used ordinary Eu clidean distance. Let $r$ and $s$ be two boreholes with $p$ variables (here $p$ is the $N$ value from surface to depth 15.0 with 1.0 meter interval, thus it is 15$)$. The two boreholes can be defined as the following vectors.

$$
\begin{aligned}
& X r=\left(x_{r 1}, x_{r 2}, \ldots \ldots, x_{r p}\right) \\
& X s=\left(x_{s 1}, x_{s 2}, \ldots \ldots, x_{s p}\right)
\end{aligned}
$$

The Euclidean distance between the two boreholes is defined as

$$
d r s^{2}=\sum_{k=1}^{p}\left(x_{r k}-x_{s k}\right)
$$

Where $d r s$ is the distance between boreholes $s$ and $r$.
The Ward's agglomeration method was used for clustering. The result of clustering is given in Fig.11. Number of cluster was decided to be four. Fig.12 il lustrates the features of each of the cluster which ob tained by averaging the $N$ value data belonging to each of the clusters. Most of the borehole data locate in the second and third groups which shows slight in creases of $N$ value with the depth. Borehole of the Lahijan area almost locate in the second group. This group is characterized by low $N$ value rate compared to the other groups. Considering high groundwater level in this area and low $N$ value rate, it might be the main factors for occurrence of liquefaction in this area during the earthquake. The liquefied area during the earthquake has a good agreement with cluster 2 .

\section{CONCLUSION}

A database system for management of site inves tigation data have been developed. The system is ca pable of producing several sets of engineering geolog ical maps. The system was applied to reveal the sub surface characteristics of Gilan plain in North - west ern Iran. Different types of maps such as lithofacies and $N$ value changes, Groundwater flow modeling,

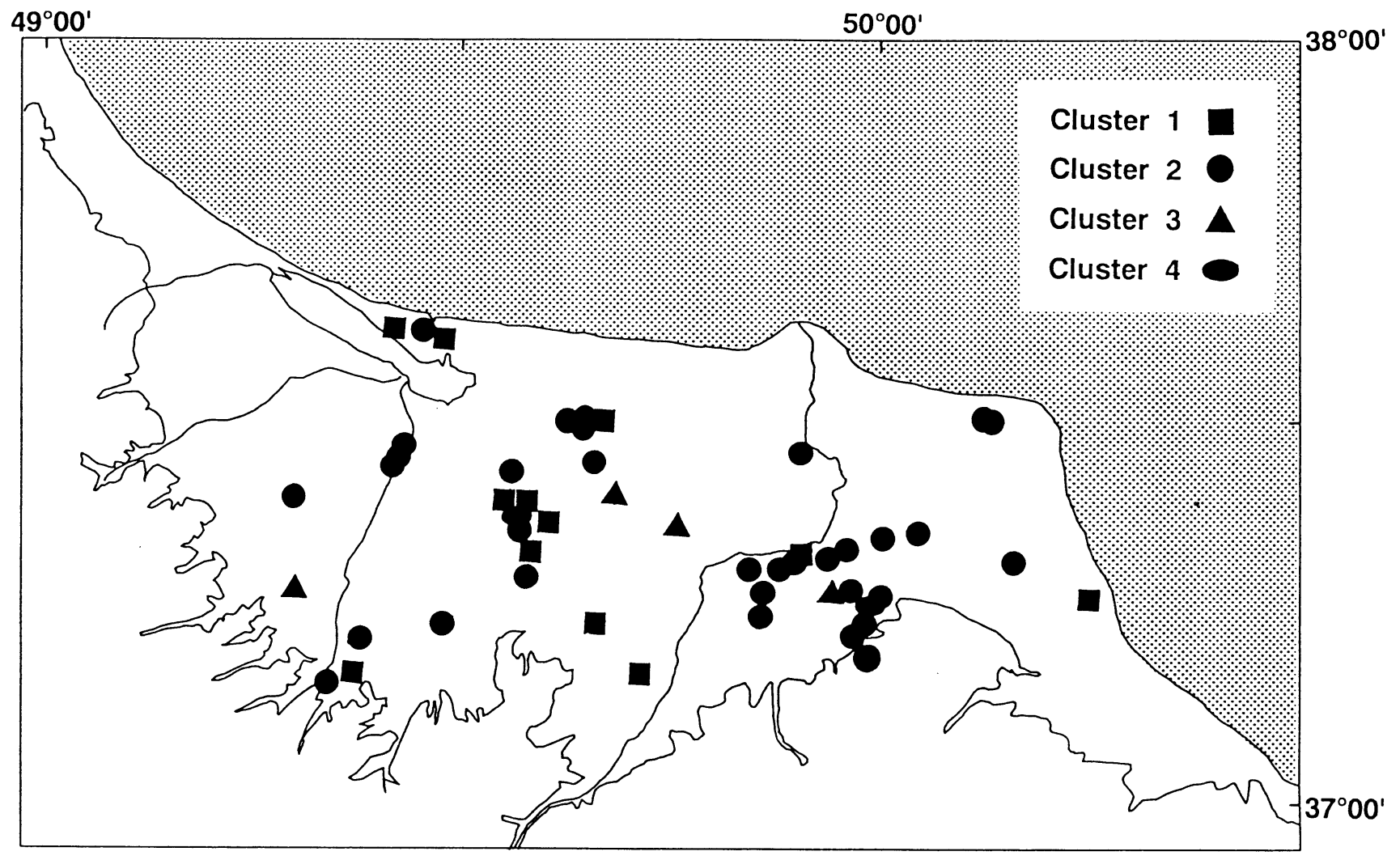

Fig.11.Cluster analysis of the $N$ values data 


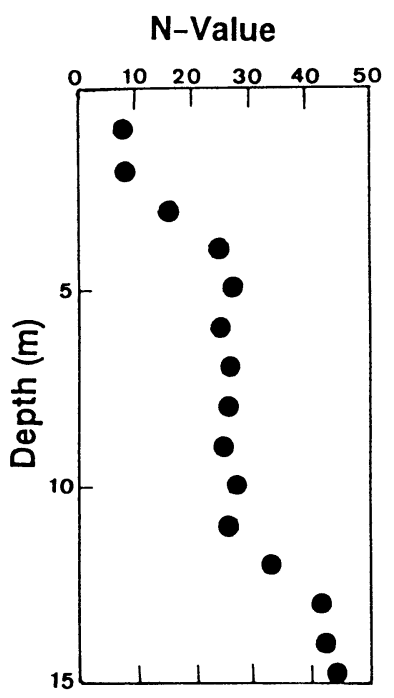

Group. 1

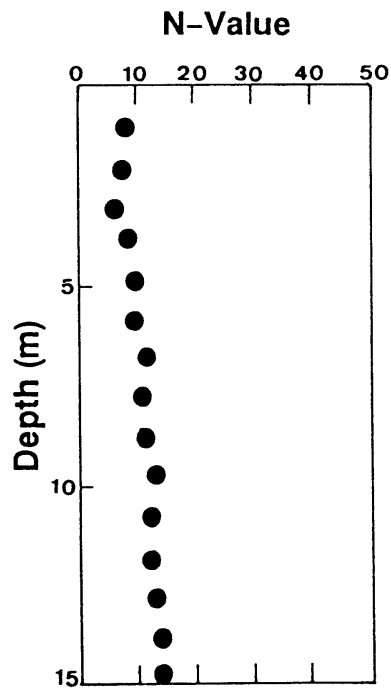

Group. 2

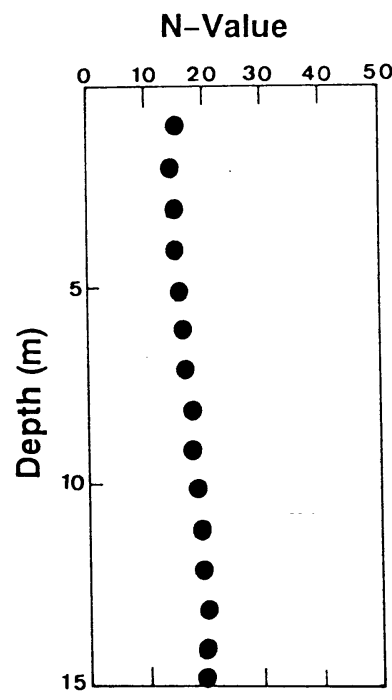

Group. 3

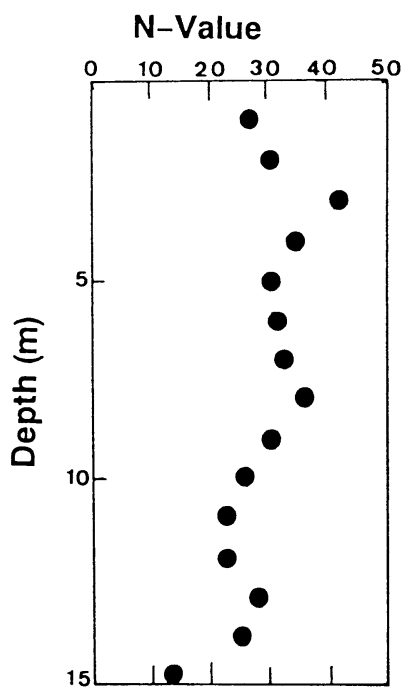

Group. 4

Fig.12.Average of $N$ values for each group

etc were produced.

The results showed that the area is mostly under lined by fine grained soils with poor geotechnical fea tures. There was a good agreement between liquefied area during the earthquake and the zone which is located in cluster 2 using cluster analysis. Also groundwater flow was estimated for the area.

\section{REFERENCES}

Akaike, H. (1973) Information theory and an exten sion of the maximum likelihood principle. 2nd In ter. Symp. on Information Theory, Akademiai kiado, Budapest, pp. 267 - 281.

Annells, R. N., et al. (1975) Explanatory text of the Qazvin and Rasht Quadrangles map. Geological Survey of Iran, nos. E3 and E4.

Bellotti, J. M., and Dershowitz, W. (1991) Hydrogeo logical investigations: Data and information management. Computer \& Geosciences, vol. 17, no.8, pp. 1119 - 1136.

Bentley, S. P., and Stenning, A. S. (1990) Strata 3: A multi-surface graphic package for the manage ment of engineering data. 6th Inter. IAEG Con gr., Balkema, Rotterdam, pp. 3 - 7.

Bottino, G., and Civita, M. (1986) Engineering geological features and mapping of subsurface in the metropolitan area of Turin, North Italy. Proc. 5th Inter. IAEG Congr., Balkema, Rotterdam, pp 79 86.

Chaplow, R. (1986) Production of borehole logs us ing a microcomputer. Quat. Jour. Eng. Geology, vol.19, pp. $291-299$.

Coulthard,J. M., et al. (1990) Integrated of standard software package and systems for unified data capture and processing. 6th Inter. IAEG Congr., Balkema, Rotterdam, pp. 9 - 15.

Davies, R.G., Hamzepour, B., et al. (1975) Explanatory text of the Bandar-e-pahlavi Quadrangle map. Geological survey of Iran.
Koike, K.,Omi, M., and Kaneko, K. (1990) Database system of geological information and its applica tion to the engineering geology. Proc. of Inter. Symp. on Advances in geological engineering, Beijing (China), pp. 175 - 184.

Forster, A. (1990) A method of producing engineer ing geology maps of Nottingham (England) for use by planner and engineers. 6th Inter. IAEG Congr., Balkema, Rotterdam.

Hayashida, Y., Mitamula, M., and Nakagawa, K. (1988) Application of urban ground database for geological studies in Osaka plain, Southwest Japan. Jour. Geosciences, Osaka City University, vol. 31, Art. 6, pp. $173-182$.

Herbschleb, J. (1990) Ingeo - base, an engineering ge ological database. 6th Inter. IAEG Congr., Balkema, Rotterdam, pp. 47 - 53.

Nakayama, H., et al. (1989) A database system for geotechnical investigation in Kumamoto area. Japan Jour. Soil \& Foundation, vol. 37, pp. 59-64 (in Japanese).

Walters, M., and Lioyd, W. J. (1985) The use of a mi crocomputer for recording and analysis of bore hole logging data in hydrogeological investiga tions. Quat. Jour. Eng. Geology, vol. 18, pp. 381 389.

Yang, Z., and Fang, H. (1990) A computer based method to analyze information of urban engineer ing geological environmental quality for engineering geological mapping. Proc. 6th Intern. IAEG Congr., Balkema, Rotterdam, pp. $79-86$. 